\title{
ANÁLISE DE PRÁTICAS DE GESTÃO DO CONHECIMENTO: ESTUDO DE CASO EM UMA MÉDIA EMPRESA DO SETOR DE SEGUROS
}

\section{ANALYSIS OF KNOWLEDGE MANAGEMENT PRACTICES: A CASE STUDY IN A MEDIUM COMPANY OF THE INSURANCE SECTOR}

\author{
André Augusto Barbosa Araújo ${ }^{1}$; Rivadávia Correa Drummond de Alvarenga Neto ${ }^{2}$ \\ ${ }^{1}$ Centro Universitário UNA - Belo Horizonte - Brasil \\ andrearaujo.bh@gmail.com \\ ${ }^{2}$ Fundação Dom Cabral - FDC - Belo Horizonte - Brasil \\ rivadavia@fdc.org.br
}

\begin{abstract}
Resumo
Este artigo investiga e analisa os processos e as práticas gerenciais existentes em uma média empresa brasileira do setor de seguros que são compatíveis com as propostas existentes na literatura sobre Gestão do Conhecimento (GC), tendo como pressuposto que a GC pode também se configurar como um processo informal e desestruturado. A estratégia de pesquisa qualitativa baseou-se em um estudo de um único caso do tipo histórico-organizacional e três critérios foram observados para o julgamento da qualidade do projeto de pesquisa: a validade do construto, a validade externa e a confiabilidade. Fontes múltiplas de evidências foram utilizadas - entrevistas semi-estruturadas, pesquisa documental e observação direta - e a análise de dados coletados em campo consistiu de três fluxos concomitantes de atividades, a saber: redução de dados, 'display' ou exibição de dados e verificação/conclusões com base em inferências a partir de evidências ou premissas. Os resultados apurados confirmaram o pressuposto supracitado e concluiu-se que, embora não formalmente, a empresa em questão possui processos e práticas de gestão compatíveis com os processos e práticas de GC relatadas na literatura. A conclusão sugere que a empresa objeto deste estudo encontra-se em estágio de maturidade para a implementação de um processo formal de $G C$.
\end{abstract}

Palavras-chave: gestão do conhecimento; práticas gerenciais; micro, pequenas e médias empresas; seguros; microsseguro.

\section{Introdução}

A transição da "velha rigidez dos átomos para a fluidez dos bits" nas organizações vem suscitando inúmeras discussões a respeito da miríade de novas terminologias, abordagens gerenciais e ferramentas criadas na denominada "Era da Informação" ou "Era do Conhecimento". Uma breve análise do cenário atual permite algumas constatações. Em primeiro lugar, a emergência de um 
novo paradigma tecno-econômico, baseado em informação, conhecimento e inovação, junto com a constatação de Stewart (1998) de que as organizações contemporâneas têm investido, cada vez mais, em bens e ativos típicos da era informacional (hardware, software, telecomunicações e redes) do que em bens e ativos típicos da era industrial (máquinas e equipamentos para engenharia de produção). Além disso, existe a percepção, por parte das cúpulas dirigentes das empresas, de que a informação e o conhecimento consolidam-se como os principais fatores de diferenciação para a competitividade organizacional. Como conseqüência, observa-se o surgimento de um sem fim de novas abordagens e/ou ferramentas gerenciais atinentes às questões da informação e do conhecimento nas organizações, sob a égide da área denominada "Gestão do Conhecimento Organizacional”. Dentre essas abordagens e/ou ferramentas, destacam-se as seguintes: gestão de conteúdo, gestão integrada de recursos informacionais, gestão estratégica da informação, gestão do capital intelectual, aprendizagem organizacional, inteligência competitiva, ontologia e memória organizacional, dentre outras. Essas diferentes perspectivas refletem diferentes concepções do que são o conhecimento e a própria organização.

Contudo, tais terminologias são frequentemente abordadas na literatura gerencial como processos formais, estruturados e muitas vezes dispendiosos em organizações de grande porte. Há exígua pesquisa sobre processos ad hoc, informais e desestruturados de Gestão do Conhecimento (GC) no contexto de pequenas e médias empresas brasileiras.

O presente trabalho é fruto de uma dissertação cujo principal objetivo foi investigar e analisar os processos e práticas gerenciais existentes em uma média empresa brasileira do setor de seguros, compatíveis com os processos e práticas discutidos e relatados na literatura sobre GC. Um pressuposto fundamental foi o de que a GC pode também se configurar como um processo informal e desestruturado, passível de aplicação no contexto de pequenas e médias empresas.

Uma premissa deste trabalho é que o conhecimento só existe na mente humana e no "espaço imaginário entre mentes criativas em sinergia de propósitos”. O conhecimento fora deste contexto é visto como informação e a GC ganha terreno a partir da compreensão de que sua terminologia é metafórica, uma vez que o conhecimento é inerente aos seres humanos e não se transfere ou se compartilha com facilidade ou espontaneidade. Reconhece-se também que a GC é fenômeno complexo e multifacetado, de conceito polêmico e controverso, e acredita-se que a expressão, embora largamente utilizada, apresenta ênfases e interfaces diferenciadas, merecedoras de análises mais meticulosas e articuladas.

Assim sendo, a problemática que se desenha no campo é aqui desdobrada na forma da seguinte pergunta de pesquisa: Quais os processos e práticas de gestão existentes em uma média empresa brasileira do setor de seguros que são compatíveis com os processos e práticas de Gestão do Conhecimento relatadas na literatura? 
Reitera-se, uma vez mais, que se tem como pressuposto que as pequenas e médias empresas podem não possuir um processo estruturado e formal de GC, embora seja possível que tenham, dentre suas atividades, práticas e ferramentas de gestão que sejam compatíveis com as práticas e ferramentas de GC relatadas na literatura. Os resultados do estudo desenvolvido serão apresentados e discutidos a seguir.

\section{O Conhecimento e sua Gestão em Organizações}

Embora muita atenção acadêmica e profissional tenha sido devotada à GC na última década, o conceito ainda não é estável. O termo aparenta ser usado de maneiras diferentes em vários domínios e cada domínio clama para si que a compreensão parcial da temática represente a articulação definitiva do conceito (DAVENPORT e CRONIN, 2000; ALVARENGA NETO, 2005, 2008).

Wilson (2002) examinou as bases de dados da "Web of Science" - em período compreendido entre 1981 e 2002 - e constatou a grande diversidade de conceitos atribuídos à GC, reafirmando toda a polêmica e controvérsia terminológica. Esse autor procurou analisar o conceito de GC a partir das proposições de três áreas interessadas pelo tema: (1) sites de empresas de consultoria, (2) análise da literatura que versa sobre o tema e (3) nas apresentações institucionais das escolas de negócios, constatando o crescimento vertiginoso e exponencial das publicações com a expressão "gestão do conhecimento".

Davenport e Cronin (2000) questionam se o termo trata de uma deriva semântica ou de uma mudança conceitual. Os autores se propuseram a explorar o conceito de GC no contexto de três domínios interessados na área, (1) biblioteconomia e ciência da informação (GC-1), (2) engenharia de processos (GC-2) e (3) teoria organizacional (GC-3). O objetivo da proposta intitulada "tríade da gestão do conhecimento" configura-se na proposição de uma ferramenta ou instrumento de análise que sirva para explorar as tensões que possam surgir em quaisquer organizações comprometidas com a GC, nas quais diferentes domínios possuam diferentes compreensões. O modelo aqui denominado "tríade da GC" pode ser utilizado para identificar conflitos ou embates territoriais e contribuir para um entendimento coletivo entre os atores do espaço da GC nas organizações. No primeiro domínio, a GC é predominantemente vista como gestão da informação. No segundo domínio, a GC é vista como a gestão do "know-how" e freqüentemente igualada à tecnologia da informação. No terceiro domínio, a GC denota uma mudança conceitual maior, do "conhecimento como recurso" para o "conhecimento como uma capacidade". Nesta última perspectiva, o que é gerenciado não é um recurso, mas o contexto em que tal prontidão é manifestada, sendo esse contexto visto como um espaço de interação entre os conhecimentos tácitos e explícitos de todos os 
membros de uma organização. As contribuições fundamentais dos autores supracitados para os objetivos deste trabalho constituem-se, respectivamente, (1) no reconhecimento da necessidade de um marco teórico conceitual para a GC, (2) na compreensão de que a gestão da informação e a tecnologia da informação são elementos constituintes de um conceito maior denominado GC e (3) em termos evolucionários, na percepção de que a mudança parte da gestão da informação (GC-1), passa pela informatização (GC-2) e aporta nas 'etologias' informacionais (GC-3). A novidade da proposta de Davenport e Cronin (2000) é a contribuição para a compreensão da natureza mutável do complexo ambiente baseado no conhecimento em que vivemos e trabalhamos.

Alvarenga Neto (2008), em extensa e profunda pesquisa qualitativa sobre a GC no ambiente brasileiro de negócios, afirma que os principais desafios impostos às organizações comprometidas com a GC concentram-se na gestão de mudanças culturais e comportamentais e na criação de um contexto organizacional favorável à criação, ao uso e ao compartilhamento de informações e conhecimentos. A partir dessa premissa, apresenta a proposta intitulada "Mapeamento Conceitual Integrativo da Gestão do Conhecimento" (QUADRO 1) e sugere que a promoção do conhecimento nas organizações deve considerar os três níveis hierárquicos que a compõem, o estratégico, o tático e o operacional: (1) uma concepção de uso estratégico da informação e do conhecimento, segundo Choo (2006); (2) a introdução dessa estratégia no nível tático, através da criação de um espaço organizacional para o conhecimento, o "ba" ou contexto capacitante, como sugerida por Von Krogh, Ichijo e Nonaka (2001); e (3) a metáfora do "Guarda-chuva Conceitual da GC" para a efetiva colocação da estratégia em ação.

Para o nível estratégico, Choo (2006) considera que as "organizações do conhecimento" utilizam a informação para atuar em três arenas distintas, porém imbricadas: (1) a construção de sentido (sensemaking) através da prospecção do ambiente organizacional em busca de informações relevantes; (2) a criação de conhecimento através do processamento das informações que geram aprendizagem organizacional e acabam por indicar caminhos para novos produtos, serviços e redesenho de processos; e (3) a tomada de decisão através do "Princípio da Racionalidade Limitada”, como advogado por March e Simon (1975).

Para o nível tático, o modelo baseia-se na criação do "contexto capacitante" ou " $b a "$, conforme Von Krogh, Ichijo e Nonaka (2001) e sugere que não há um efetivo gerenciamento do conhecimento, uma vez que o mesmo é intrínseco ao ser humano. Dessa forma, o que pode ser gerenciado é o "contexto capacitante" - o conjunto de condições favoráveis que devem ser propiciadas pela organização, para favorecer o compartilhamento, a aprendizagem, a solução colaborativa de problemas e a tolerância aos chamados "erros honestos", dentre outros.

Para o nível operacional é utilizada a metáfora do "Guarda-chuva Conceitual da GC" (ALVARENGA NETO, 2008) pressupondo que, debaixo desse, alojam-se diversos temas 
orientados para as questões da informação e do conhecimento nas organizações, tais como: gestão estratégica da informação, gestão do capital intelectual, aprendizagem organizacional, inteligência competitiva e comunidades de prática, dentre outros.

Quadro 1: Mapeamento Conceitual Integrativo da Gestão do Conhecimento

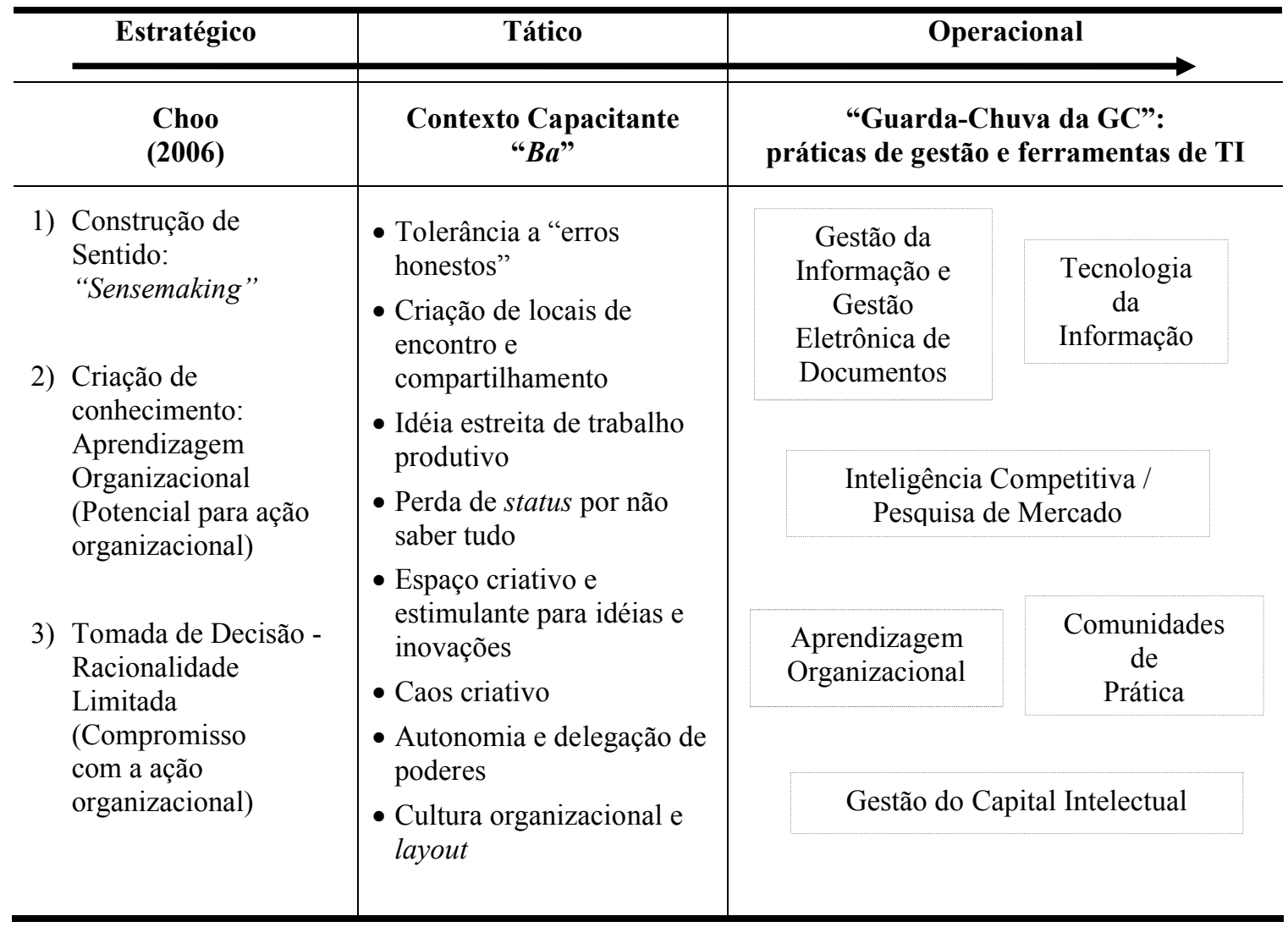

Fonte: Adaptado de ALVARENGA NETO, (2008, p. 207).

A partir do referencial teórico aqui discutido, esta pesquisa se utilizou de um modelo de análise dividido em quatro categorias analíticas para investigar as práticas ou o conjunto de práticas associados à GC, a saber: (1) monitoração ambiental e inteligência competitiva; (2) gestão estratégica da informação; (3) gestão do capital intelectual; e (4) comunidades de prática e aprendizagem organizacional. Tais categorias são condizentes com a literatura acerca da GC e serão discutidas, cada uma delas, nas próximas seções deste artigo.

\section{Monitoração Ambiental e Inteligência Competitiva}

De acordo com Choo (2006), o ambiente externo pode ser visto como uma fonte de informações, uma combinação de recursos ou um "ambiente ecológico". A perspectiva do ambiente como fontes de informações é claramente elucidada por Dill (1962): 
[...] tratar o ambiente como informações que se tornam disponíveis para a organização ou para as quais a organização, através de atividades de busca e pesquisa, pode obter acesso. Não é o fornecedor ou o cliente que contam, mas a informação que ele torna acessível para a organização sendo estudada a respeito de seus objetivos, as condições sob as quais ele entrará em um contrato ou outros aspectos de seu comportamento (DILL, 1962).

Na visão do ambiente externo como fonte de informações, Choo (2006) afirma ainda que a busca de informações no ambiente tem por objetivo reduzir a incerteza, auxiliando o processo decisório, e considera que a organização busca a monitoração ambiental, para garantir a sua adaptação imediata e criar condições favoráveis de prosperidade a longo prazo. Esse processo sugere uma seqüência de atividades cronologicamente alinhadas, pois primeiramente é necessário perceber o ambiente, para depois buscar, construir e interpretar.

Barbosa $(1997,2002)$ afirma que existem vários outros conceitos associados aos de monitoração ambiental e que a diferença entre eles - inteligência empresarial, inteligência do concorrente, inteligência competitiva, inteligência social e 'issues management' - pode ser compreendida a partir da perspectiva de duas variáveis que são o escopo da coleta de dados e o horizonte temporal.

Alvarenga Neto (2005), em seu estudo sobre práticas de GC em empresas brasileiras, constatou a existência das seguintes práticas de monitoração ambiental, inteligência competitiva e atividades correlatas, nas organizações estudadas por ele: (1) Processos formais e estruturados Clippings (produzidos internamente ou externamente); pesquisas de mercado; buscas auxiliadas por bibliotecários; participações em seminários; assinaturas de jornais e periódicos; inteligências do concorrente, competitiva e monitoração ambiental; benchmarking; sistemas de informações e bases de dados (externos, como Reuters, Factiva, Dow Jones, entre outros). (2) Processos informais e desestruturados - Viagens internacionais; contatos com pessoas; internet; boatos; "colaboradores pinçam algo no mercado"; networking e trabalhos de campo dos colaboradores.

\section{Gestão Estratégica da Informação}

Para Davenport (1998, p.173-174), Gerenciamento da Informação (GI) é o "conjunto estruturado de atividades que incluem o modo como as empresas obtêm, distribuem e usam a informação e o conhecimento." Ainda segundo o autor, (1998, p. 175), um processo genérico de gerenciamento da informação possui quatro fases: (1) determinação das exigências das informações; (2) obtenção de informações; (3) distribuição das informações e (4) utilização das informações.

McGee e Prusak (1995, p.53) consideram que o GI deve ser tratado de forma estratégica, inclusive fazendo parte integral do planejamento estratégico das organizações. Segundo os autores, 
os elementos para a definição da estratégia organizacional devem ser conjugados aos objetivos informacionais e aos da tecnologia. Destarte, a arquitetura informacional, de acordo com McGee e Prusak (1995), diz respeito a um guia para estruturar e localizar a informação dentro da organização. Seu objetivo deve ser o de ligar as novas tecnologias às orientações estratégicas empresariais, limitando o universo da informação e definindo qual informação é mais importante para a organização.

Em suas pesquisas, Alvarenga Neto (2005) observou a existência das seguintes práticas de gestão estratégica da informação, gestão eletrônica de documentos, mapeamento de processos e tecnologia da informação: (1) Gestão estratégica da informação, Gestão Eletrônica de Documentos (GED) e mapeamento de processos; workflow; criação de repositórios únicos para a informação organizacional; taxonomias e processos de disseminação seletiva da informação; bibliotecas corporativas; centros de documentação e arquivística; bibliotecas digitais; árvores de decisão; definição de ciclo de vida da informação; tabelas de temporalidade e descarte de documentos; tratamento e organização da informação; gestão de conteúdo; gestão de projetos; gestão de processos e redesenho de processos organizacionais; organização de arquivos físicos e eletrônicos e mapeamento do acervo público das organizações. (2) Tecnologia da informação: Redes; intranets; softwares e ferramentas; digitalização; segurança de informações; bases de dados.

\section{Capital Intelectual}

De acordo com Stewart (1998), o Capital Intelectual (CI) é a soma dos conhecimentos de todos em uma empresa, o que lhe proporciona vantagem competitiva. O autor aponta três locais, onde considera ser possível encontrar o CI: pessoas, estruturas e clientes. Esses locais, uma vez desdobrados, apontam para três modelos de capital: (1) capital humano, (2) capital estrutural e (3) capital do cliente.

Edvinsson e Malone (1998) acreditam que o CI é muito valioso porque conduz ao estudo aprofundado das raízes de uma empresa e às mensurações dos fatores dinâmicos que dão suporte à empresa visível. Na perspectiva dos ativos intangíveis de uma organização, esses autores discutem questões como patentes, propriedade intelectual, marca, reputação e mensuração do valor dos relacionamentos de longo-prazo entre a organização e seus clientes, dentre outros.

Alvarenga Neto (2005) verificou a existência das seguintes práticas de gestão de capital intelectual em pesquisa no ambiente brasileiro de negócios: (1) Gestão do capital intelectual e ativos intangíveis: Patentes, royalties e registros. (2) Gestão de competências e programas de acompanhamento de aposentadorias. (3) Programas de idéias e sugestões: idéias que fortaleçam as competências essenciais da organização e seu portfólio de conhecimentos. 
(4) Sistemas localizadores de expertise (Yellow Pages ou páginas amarelas corporativas).

(5) Gestão de competências, treinamento e desenvolvimento.

\section{Aprendizagem Organizacional e Comunidades de Prática}

Garvin (1993) define uma organização inteligente como uma organização que aprende e que é hábil na criação, aquisição e transferência de conhecimento. Tal organização também é habilidosa na modificação de seu comportamento para refletir o novo conhecimento, as novas idéias e os novos 'insights'. Ainda de acordo com Garvin (1993), para que uma empresa se transforme em uma verdadeira organização de aprendizagem é necessário atinar para três temas críticos: (1) significado ('meaning') - definição clara, bem fundamentada e facilmente aplicável da organização que aprende; (2) gestão ('management') - diretrizes operacionais mais claras acerca de aspectos práticos; (3) mensuração ('measurement') - para avaliar a velocidade, a viscosidade e os níveis de aprendizado da organização.

Senge (2000), pioneiro nas propostas e estudos sobre aprendizagem organizacional (AO), apresenta uma definição interessante sobre 'as organizações que aprendem':

\footnotetext{
Organizações nas quais as pessoas expandem continuamente sua capacidade de criar os resultados que realmente desejam, onde se estimulam padrões de pensamentos novos e abrangentes, a aspiração coletiva ganha liberdade e onde as pessoas aprendem continuamente a aprender juntas. (SENGE, 2000).
}

A partir desses pressupostos, Senge (2000) apresenta as cinco disciplinas que considera vitais para a organização que aprende e que devam ser desenvolvidas em conjunto, de forma integrada: (1) domínio pessoal; (2) modelos mentais; (3) construção de uma visão compartilhada; (4) aprendizagem em equipe; (5) pensamento sistêmico.

Davenport e Prusak (1998) sugerem estratégias simples e eficazes para a criação e transferência de conhecimento, e, por conseqüência, geradores de aprendizado organizacional: criação de locais e espaços de encontro e compartilhamento, realização de feiras e fóruns abertos do conhecimento e layout - em termos físicos e virtuais, dentre outros. Senge (2000) compartilha da visão dos autores, ao discutir a disciplina denominada "construção de uma visão compartilhada".

Alvarenga Neto (2005) constatou a existência das seguintes práticas de AO nas organizações que estudou: (1) Apoio à formação continuada: Especialização; $M B A$; mestrado e doutorado; idiomas - com liberação de tempo e pagamento integral do salário. (2) Profissional com expertise deve explicar assunto para outros interessados: grupos presenciais de estudo, sessões de atualização técnica. (3) e-learning e cursos à distância. (4) Universidades corporativas e parcerias com universidades. (5) Bancos de melhores práticas. (6) Programas internos de treinamento e 
desenvolvimento, centros de auto-instrução, programas de treinamento - com as áreas de recursos humanos, comercial e de tecnologia de informação.

A temática das comunidades de prática se vincula à da aprendizagem organizacional. Assim, considera-se que um dos pilares da GC é o reconhecimento e a compreensão das chamadas “comunidades de prática”, capazes de geração de aprendizagem organizacional.

Wenger e Snyder (2001, p.10) definem Comunidades de Prática (COPs) como um grupo de pessoas informalmente unido pelo conhecimento especializado e compartilhado, relacionado a um empreendimento em comum. Os membros dessas comunidades podem fazer parte da mesma estrutura organizacional ou até mesmo se encontrarem geograficamente dispersos, o que configurará uma comunidade de prática real ou virtual. A pedra angular consiste na determinação do reconhecimento ou não, pelas organizações, do valor do conhecimento gerado pelas COPs. Essas comunidades podem oferecer soluções e alternativas que se encaixem perfeitamente às diretrizes do planejamento estratégico organizacional.

As práticas de COPs identificadas por Alvarenga Neto (2005) nas organizações que pesquisou são: (1) Comunidades reais de prática - Reuniões, sessões de atualização técnicas, "rodas de bate-papo". (2) Comunidades virtuais de prática - Participação em comunidades virtuais internas e externas à organização; extensão e abertura das comunidades para atores do ambiente organizacional externo - clientes, parceiros, entre outros; utilização de tecnologias de colaboração síncronas (chats, conference call, videoconferência) e assíncronas (news, knowledge library, fóruns de discussão, gestão de documentos, pedidos urgentes), compartilhamento de melhores práticas e aprendizagem.

Concluídas as questões atinentes ao referencial teórico - que conferirão sustentação e robustez aos instrumentos de coleta e permitirão que se responda ao problema de pesquisa em questão - prosseguir-se-ão, na próxima seção, os procedimentos metodológicos.

\section{Procedimentos Metodológicos}

Trata-se de uma pesquisa qualitativa, de natureza descritiva quanto aos fins e um estudo de caso do tipo histórico-organizacional quanto aos meios.

O trabalho em questão adotou procedimentos metodológicos conceituados como estudo de caso único com unidades de análise holísticas (YIN, 2001).

Yin (2001), considera que o caso único pode ser utilizado para determinar se as proposições de uma teoria são corretas ou se algum outro conjunto alternativo de explanações pode ser mais relevante. Dessa forma, justifica-se a classificação da presente pesquisa, quanto aos meios, como 
estudo de caso único, já que o propósito é realizá-la em uma empresa privada do setor de seguros (amostra intencional, não probabilística, por conveniência ou facilidade de acesso).

Foram utilizadas generalizações analíticas, que de acordo com Yin (2001), são próprias para estudos de caso no qual se busca generalizar a compilação de resultados específicos da pesquisa dentro de um modelo teórico. Neste caso, utilizaram-se categorias analíticas a partir do "Mapeamento Conceitual Integrativo da Gestão do Conhecimento" proposto por Alvarenga Neto (2005, 2008), que trata de processos de GC nas organizações. Buscou-se investigar as seguintes práticas de GC na empresa estudada: Inteligência Competitiva (IC) e Monitoração Ambiental (MA); Gestão Estratégica da Informação (GEI); Gestão do Capital Intelectual (CI); Aprendizagem Organizacional (AO) e Comunidades de Prática (COPs).

Cada uma das práticas citadas foi tratada como uma categoria de análise da pesquisa e remetida, diretamente, a um objetivo específico. Segundo Alvarenga Neto, Barbosa e Cendón (2006, p.79) “a intenção ao se estabelecer categorias é a de agrupar elementos, idéias e expressões em torno de conceitos capazes de sintetizar a análise meticulosa dos estudos de caso selecionados." A partir desta estratificação, foram criadas unidades de análise para melhor desenvolvimento da análise dos dados coletados em campo.

Quanto ao julgamento da qualidade do projeto de pesquisa, optou-se pelos seguintes critérios sugeridos por Yin (2001, p.105): (1) fontes múltiplas de evidências; (2) banco de dados para o estudo de caso; e (3) encadeamento de evidências. Segundo o autor, esses são fatores que aumentam substancialmente a qualidade de um estudo de caso.

Com base no arcabouço teórico, buscou-se, em cada uma das unidades de análise, o levantamento de evidências que comprovassem a existência ou inexistência de processos de GC na empresa. Para tanto, optou-se pela utilização de múltiplas fontes de evidências através da fundamentação lógica de triangulação que, segundo Yin (2001), "reforça o constructo e solidifica os resultados". Nesse sentido, foram utilizados os seguintes instrumentos de coleta de dados: (1) entrevistas semi-estruturadas: perguntas previamente formuladas, que servem para corroborar o que o investigador pensa a respeito de determinada situação (TRIVIÑOS, 1987; YIN, 2001), (2) pesquisa documental (documentos físicos e arquivos eletrônicos) e (3) observação direta. Tais instrumentos de coleta foram representados na forma de um protocolo de estudo de caso que, por sua vez, foi concebido a partir de cada uma das quatro categorias analíticas.

Foram entrevistados representantes dos níveis estratégico, tático e operacional da organização. Com vistas a um maior aprofundamento e compreensão dos fenômenos observados, optou-se por uma avaliação crítica e comparativa entre as respostas intra e inter-hierárquicas.

Para realizar a análise de dados coletados em campo, foi utilizado o modelo proposto por Miles e Huberman (1984), que propõem a análise de dados dividida em três etapas: (a) redução de 
dados, (b) Display ou exposição de dados e (c) verificação/conclusões com base em inferências a partir de evidências ou premissas, conforme a FIG. 1:

Figura 1 - Componentes da análise de dados: Modelo Interativo

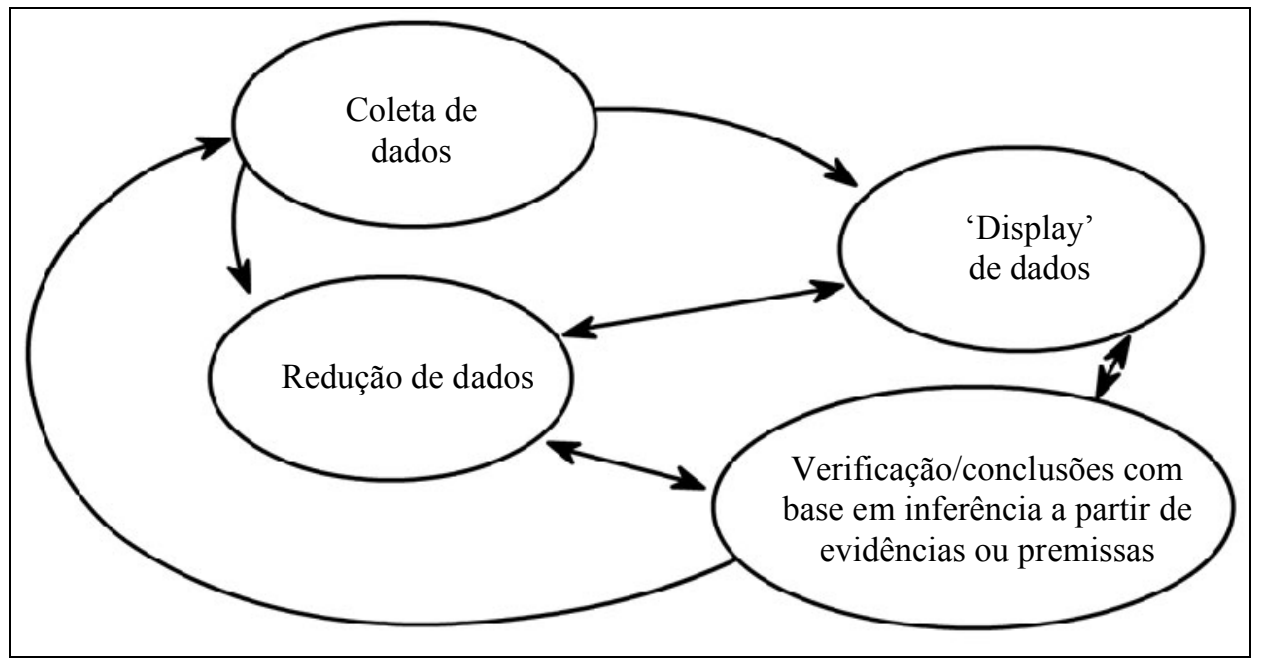

Fonte: Adaptado de MILES e HUBERMAN, (1984, p. 23).

Os resultados da pesquisa serão apresentados e discutidos na próxima seção.

\section{Pesquisa de Campo: Apresentação e Análise dos Principais Resultados}

A empresa investigada é a XYZ Administradora e Corretora de Seguros Ltda. (nome fictício, para resguardar a identidade e preservar o sigilo das informações sensíveis da empresa, conforme contrato de confidencialidade assinado entre as partes).

A XYZ é uma empresa do setor de seguros com mais de 19 anos de mercado que tem como principal produto o denominado "microsseguro de vidas". A pesquisa documental revela que atualmente a empresa possui um número aproximado de 2 milhões de segurados (entre titulares e dependentes), mais de 13 mil convênios vigentes, 3 mil corretores cadastrados em todo o Brasil, está presente nos 27 estados da Federação e é parceira de mais de 300 entidades de classe. Os valores indenizados ao longo dos 19 anos de vida da empresa ultrapassam 70 milhões de reais, refletidos em mais de 23 mil indenizações efetivadas. Seu faturamento anual é da ordem de 30 milhões de reais e tem mantido uma média de crescimento anual em torno de 30\%. Possui 53 funcionários e está instalada em Belo Horizonte - MG. Tomando-se por base a classificação de empresas por porte segundo o SEBRAE (2005), constata-se que a empresa objeto de estudo está classificada como uma média empresa do setor de serviços do Brasil.

Outra fonte de evidências utilizada para o desenvolvimento da pesquisa foi a entrevista semi-estruturada. Para isso, foi utilizado como instrumento de coleta de dados um Protocolo de 
Estudo de Caso, construído de acordo com as categorias de análise, que procurou contemplar todos os procedimentos a serem seguidos, de forma a nortear a investigação e buscar responder ao problema de pesquisa. Foram realizadas, ao todo, nove entrevistas, sendo duas com a área estratégica da empresa (presidência e diretoria executiva), quatro com o nível tático (coordenadores de quatro setores distintos) e três com a área operacional (colaboradores de três áreas distintas da empresa). Para melhor compreensão, a reprodução de citações dos entrevistados serão aqui identificadas por sua autoria como: "Presidente", "Diretora Executiva", "Tático" e "Operacional", sendo que os níveis tático e operacional serão numerados por sua ordem de entrevista. Ressalte-se que todas as entrevistas foram gravadas, com o devido consentimento dos entrevistados, e totalizaram 810 minutos (13 horas e 30 minutos) de gravação. Utilizou-se também, confrome relatado no início desta seção, de farta pesquisa documental, além da observação direta, sempre que possível.

Durante a análise dos dados, todas as entrevistas foram ouvidas na íntegra e detalhadamente pelo pesquisador. Na busca por evidências, em vários momentos foi necessário ouvir trechos por mais de uma vez, sendo que os mais relevantes foram transcritos para a realização do primeiro "Display", conforme metodologia de análise de dados sugerida por Miles e Huberman (1984). Uma constatação preliminar permitiu identificar, na medida em que se caminhava na estrutura hierárquica da empresa, dos níveis mais baixos para os mais altos, que os resultados tornavam-se mais consistentes e as entrevistas ficavam com maior riqueza de informações. Optou-se por apresentar e analisar os resultados a partir de cada categoria de análise, uma vez que cada uma delas reflete um dos objetivos específicos que, por sua vez, convergem rumo ao objetivo geral desta pesquisa. Seguem as análises de cada uma dessas categorias:

\subsection{Categoria de Análise 1: Inteligência Competitiva (IC) e Monitoração Ambiental (MA)}

Observou-se que a IC e a MA são praticadas na empresa nos três níveis hierárquicos. Entretanto, não se pode afirmar que sejam praticadas em todas as coordenadorias setoriais. Nos ambientes em que essas práticas foram identificadas, as mesmas apareceram de maneiras distintas. A importância de se coletar informações no ambiente foi destacada pelos três níveis hierárquicos, principalmente informações relacionadas à concorrência e aos clientes (atuais e futuros). Evidências maiores indicaram que a IC e MA são mais realizadas pelo setor comercial e pela diretoria da empresa.

\footnotetext{
"Na verdade, isso chega prá gente (sic) naturalmente, através da área comercial. [...] Nós monitoramos principalmente o ambiente mercadológico e político. Quem mais monitora somos eu, o presidente, e todas as pessoas que estão no nível de coordenação hoje fazem isso." (Diretora Executiva)
} 
Através da pesquisa documental, foram encontrados indícios de que uma das práticas mais utilizadas pela empresa para realizar a monitoração ambiental seria a participação em eventos diversos. Foram encontradas várias evidências que comprovaram esta participação tanto em eventos do setor de seguros, quanto em eventos dos setores de seus clientes e/ou parceiros.

\footnotetext{
"Participa de congressos como o do SINCOR [Sindicato dos Corretores de Seguros], o próprio ENIC [Encontro Nacional da Indústria da Construção], principalmente dos ligados ao setor da construção civil, que é o nosso principal público-alvo.” (Operacional 3)

"Participamos de eventos de diversas maneiras: como palestrantes, congressistas, patrocinadores, etc. Porque ali é o mercado né (sic)...” (Diretora Executiva)

"[...] Avaliando os produtos e serviços destes eventos eu posso comparar ao nosso e avaliar muito bem em que situação nós nos encontramos com o nosso. Ele me traz muita informação com muita riqueza de parâmetros, para que eu possa avaliar em que campo nós ainda não estamos... Ou que espaço nós ainda precisamos atuar... Isso tudo me ajuda muito!" (Presidente)
}

Uma das evidências que podem comprovar a valorização que a empresa dá a esta fonte de informações acerca de seu ambiente externo é sua constante participação em eventos setoriais, conforme comprovado pela FIGURA 2:

Figura 2 - Patrocínio da empresa para o $80^{\circ}$ ENIC: Encontro Nacional da Indústria da Construção (2008)

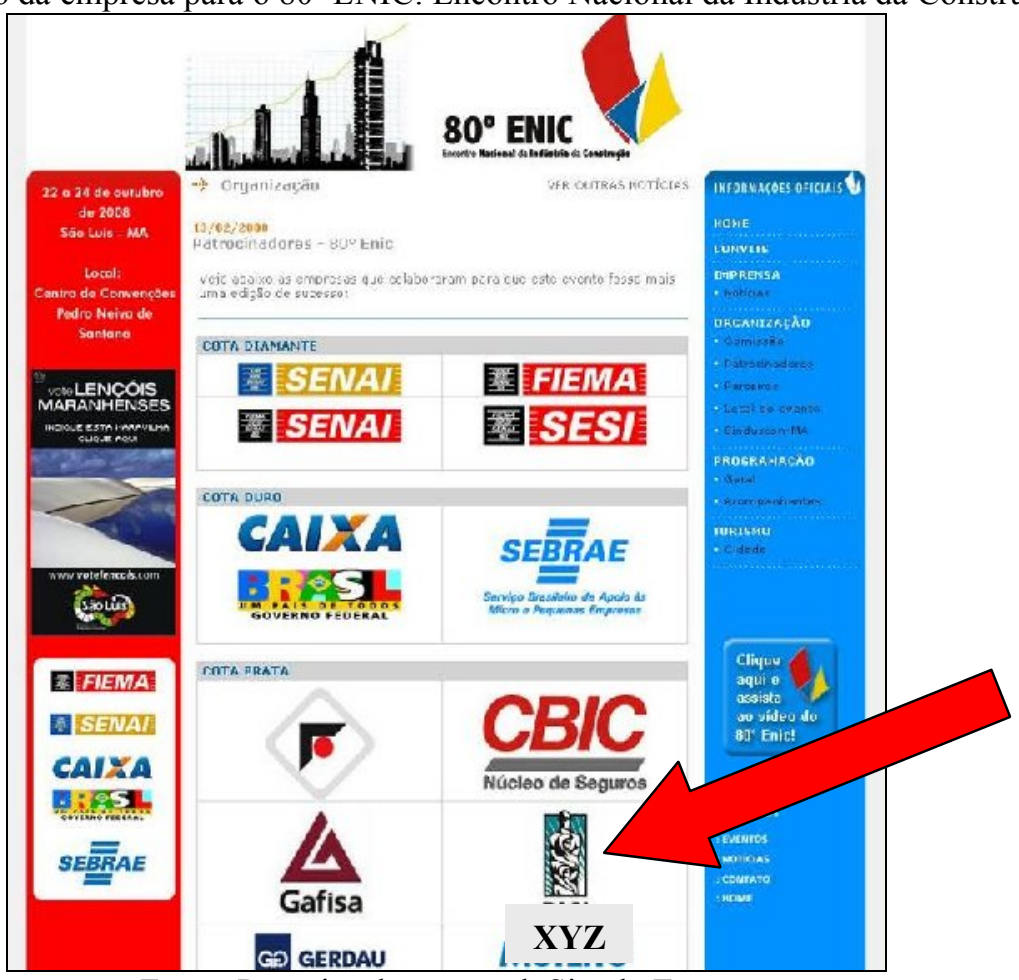

Fonte: Pesquisa documental, Site do Evento 
Outra fonte de informações do ambiente para a empresa são as publicações e periódicos. Através das entrevistas, foram citadas a existência de periódicos assinados pela empresa. Também pôde-se observar publicações de parceiros de negócios disponíveis na recepção da empresa.

As práticas de IC e MA identificadas na organização investigada foram: (1) Participações em seminários; (2) Assinaturas de jornais e periódicos; (3) "Colaboradores pinçam algo no mercado"; (4) Inteligências do concorrente, competitiva e monitoração ambiental.

Observa-se assim que existem práticas de IC e MA na empresa, embora não exista um processo formalizado, que defina como essas práticas devam ser desenvolvidas.

\subsection{Categoria de Análise 2: Gestão Estratégica da Informação (GEI)}

Constatou-se uma grande importância dada à informação pela organização. Ao serem questionados se a empresa praticava a GEI, as respostas apontaram para os estágios iniciais de um processo. Uma parte dos entrevistados estabeleceu uma relação direta entre a GEI e o principal Sistema de Informações da empresa, denominado "SCGP" (Sistema de Controle e Gestão de Produto). Ao investigar a forma que a empresa organiza, trata, classifica e indexa a informação, apenas um entrevistado do nível operacional disse não saber. Para os demais entrevistados a resposta foi unânime: através do SCGP. Os depoimentos abaixo confirmam tal assertiva:

\footnotetext{
“A empresa tem GEI, principalmente através do sistema SCGP.” (Operacional 3)

“Com o novo sistema (SCGP), a gente está com uma riqueza de informação. [...] Hoje a gente tem uma base de dados e uma base de informação para a nossa análise de mercado... de produto mesmo, muito grande. O meu problema maior hoje é fazer com que as pessoas entendam o que elas têm na mão para processar como informação e usar isso a nosso favor." (Diretora Executiva)
}

Pôde-se observar, ainda, que o SCGP favorece à tomada de decisões para a empresa, através dos seus relatórios. A diretoria foi apontada como a grande tomadora de decisões da empresa. Foi possível identificar também que o SCGP já começa a favorecer à tomada de decisões em outros níveis hierárquicos.

"Recentemente estamos tendo apoio para tomada de decisão através do SCGP." (Operacional 2)

Foi constatado que a diretoria considera existir arquitetura informacional na empresa através do SCGP. Nos níveis tático e operacional, os entrevistados julgaram que a arquitetura informacional esteja apenas iniciando ou, em alguns casos, que não exista.

Através do organograma organizacional, observou-se a existência formalizada de um setor de Tecnologia da Informação (TI) na empresa, e a maioria dos entrevistados o reconheceu como o 
responsável pela GEI. Entretanto, uma outra ocorrência freqüente nesta questão foi a relação entre o setor de Marketing e a GEI. Esta evidência apareceu nos níveis operacional e tático. Dessa forma, as respostas apontaram para a TI e para a área de Marketing como responsáveis pela GEI. Presumese que esta co-relação entre o Marketing e a GEI, tenha sido estabelecida devido ao destaque dado ao setor de Marketing como sendo um dos grandes disseminadores de informações dentro da empresa, através de publicações periódicas (ex: notícias através de um jornal mensal, informações através do e-mail - FIG. 3, mural de informações, etc.).

Figura 3 - Informações enviadas através de e-mail pelo Depto. Marketing

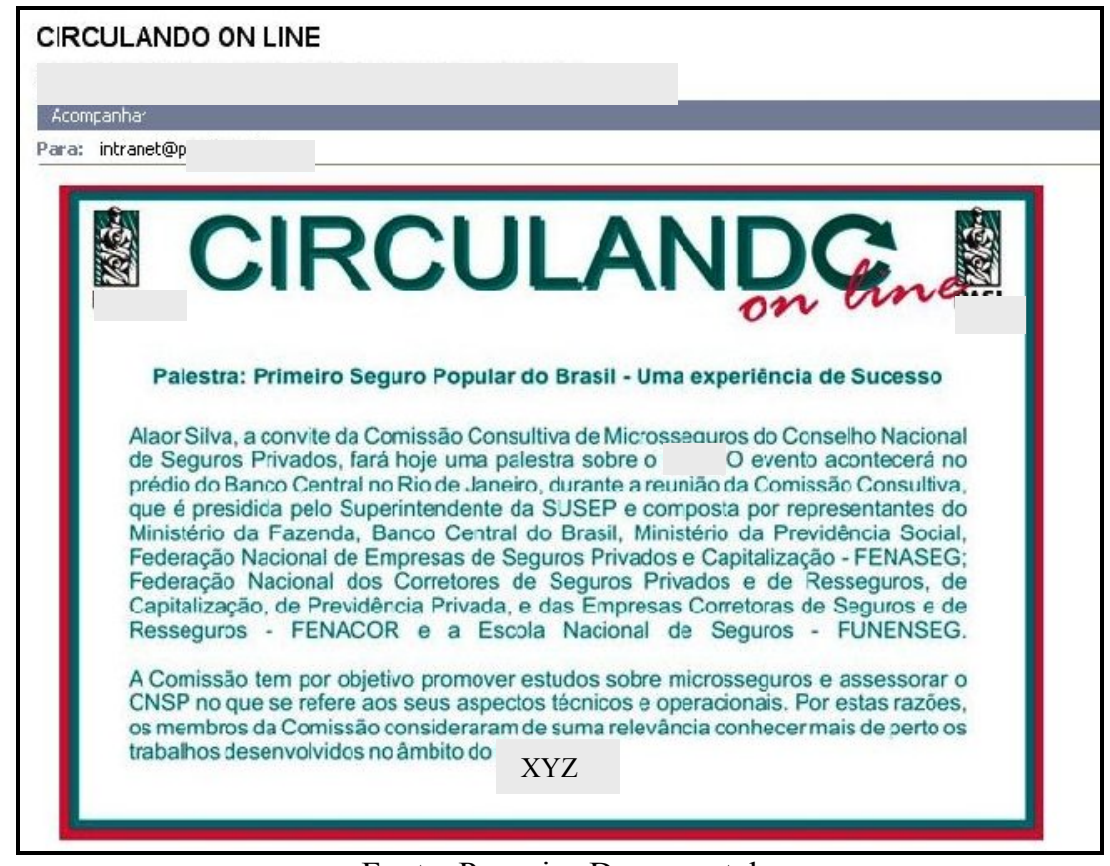

Fonte: Pesquisa Documental

Durante a análise de práticas de GEI, foi feita também uma investigação, buscando identificar se as informações necessárias para a empresa eram encontradas em tempo hábil por seus solicitantes. O resultado apresentou-se inconclusivo, já que não houve consenso entre os entrevistados: enquanto alguns julgavam que as informações eram encontradas em tempo hábil, outros consideravam que não, relatando inclusive reclamações dos usuários. Foram encontrados na empresa muitos documentos armazenados em formato físico, acomodados em pacotes pardos e caixas-arquivo. Constatou-se que esses documentos, eventualmente, precisam ser consultados em processos rotineiros, e sua recuperação nem sempre é rápida. Este fato pode justificar as reclamações quanto ao tempo de encontro das informações.

Ao investigar a existência ou não de iniciativas de GED (Gestão Eletrônica de Documentos) foi identificada uma única prática: a Importação Eletrônica de Segurados. É uma prática específica, desenvolvida em um único setor da empresa, e funciona como um importador automático de dados de clientes para o seu banco de dados. 
Um fato a ser destacado é a preocupação da empresa com a proteção de suas informações sensíveis, tanto no seu sistema de informações quanto nos acessos aos documentos eletrônicos, através da restrição de acesso às áreas de armazenamento de dados no servidor de arquivos da empresa.

\footnotetext{
"Há restrições ao acesso a determinadas informações, bloqueadas pelo acesso ao SCGP." (Operacional 1)

"Certos tipos de informação não são passados ou são passados somente aos coordenadores. Outros tipos de informações são bloqueados em sistema, só permitindo acesso a quem realmente precisa." (Diretora Executiva)
}

O maior produto informacional da empresa, segundo as evidências levantadas, são os relatórios que apóiam a tomada de decisões. Esta percepção foi identificada em todos os três níveis hierárquicos, com especial destaque para um relatório denominado "Resultado Geral" que espelha um resumo de resultados operacionais da empresa em um determinado prazo.

Dessa forma, observou-se a existência das seguintes práticas de GEI na organização estudada: (1) Gestão eletrônica de documentos (GED); (2) Criação de repositórios únicos para a informação organizacional; (3) Tratamento e organização da informação; (4) Organização de arquivos físicos e eletrônicos; (5) Tecnologia da informação: rede; softwares e ferramentas; digitalização; segurança de informações; bases de dados.

Constatou-se, assim, que existem práticas de GEI, embora as mesmas não sejam definas segundo um processo formal de como devam ser desenvolvidas.

\subsection{Categoria de Análise 3: Gestão do Capital Intelectual (CI)}

Para o nível estratégico da organização, a gestão do CI encontra-se em estágios embrionários. Nos níveis tático e operacional esta questão mostrou-se inconclusiva.

Apesar dos entrevistados dos níveis operacional e tático afirmarem não existir nenhuma iniciativa de mapeamento de CI na empresa, foi observada uma iniciativa da Coordenadoria de Recursos Humanos em se reunir e entrevistar cada um dos Coordenadores dos demais setores da empresa para realizar um mapeamento de competências - iniciativa que pode ou não, futuramente, se configurar como um sistema localizados de expertise:

"O RH vai desenvolver um sistema localizador de expertise. Já está começando a fazer isso." (Diretora Executiva)

"Agora temos uma pessoa de RH que cuidará disso [gestão de competências]." (Presidente) 
$\mathrm{Na}$ investigação de como encontrar o melhor conhecimento organizacional na empresa, os indícios apontaram para um processo informal, através de consultas pessoais aos funcionários mais antigos na organização. Também foi ressaltada a importância do organograma nesse processo:

\footnotetext{
"A empresa mapeia pela própria hierarquia que ela adota. Se você for procurar a pessoachave em cada setor, provavelmente você vai buscar na coordenação. [...] está bem delineado no organograma da empresa." (Operacional 3)
}

Contudo, o organograma não aponta, necessariamente, para o melhor conhecimento disponível nas mentes dos colaboradores. Ele indica unicamente para o colaborador em cargo de chefia, que não é necessariamente o possuidor do melhor conhecimento organizacional disponível.

Durante a investigação do valor dado aos ativos intangíveis, foi observada uma preocupação muito grande da empresa com a sua marca. Os três níveis hierárquicos destacaram esta preocupação e apontaram a diretoria como o setor que cuida deste assunto na empresa. Ao levantar evidências através de pesquisa documental e observação direta, foi possível observar orientações detalhadas da Diretora Executiva e do setor de Marketing para um parceiro que desejava inserir a logomarca da empresa XYZ em seu site na Internet. Segundo a Diretora, esta é uma situação corriqueira na organização. Tal fato comprova a preocupação que a empresa nutre por sua marca.

Com relação à existência ou não de um programa de sugestões e idéias que objetive fortalecer as competências essenciais da empresa e seu portfólio de conhecimentos, o resultado foi inconclusivo. Conforme ressaltado anteriormente, constatou-se que a Coordenadoria de RH já inicia um processo de mapeamento de competências, que poderá evoluir ou não para um sistema localizador de expertise. Desta forma, não foi observada nenhuma evidência que sugira a existência de processos de gestão por competências, sistema localizador de expertise ou programa para acompanhamento de aposentadorias.

Assim, foi possível identificar apenas duas práticas de CI já existentes: (1) Mapeamento de competências (processo em fase inicial) e (2) Gestão de ativos intangíveis: marcas.

Evidencia-se, dessa forma, a existência de práticas de CI, mesmo que de maneira informal, embrionária e incipiente.

\subsection{Categoria de Análise 4: Aprendizagem Organizacional (AO) e Comunidades de Práticas (COPs)}

Não foram encontradas COPs na organização, apenas práticas associadas à AO.

Ao serem indagados sobre a $\mathrm{AO}$, os entrevistados do nível operacional a associaram diretamente aos incentivos que a empresa dá a alguns de seus funcionários para o desenvolvimento de seus estudos, como subsídios e flexibilização de horários. Os entrevistados do nível tático não 
consideraram existir AO na empresa. O nível estratégico observou uma evolução na AO, através do nível intelectual dos mais recentes colaboradores contratados pela empresa. Contudo, tais práticas não são indicativos de aprendizado organizacional, mas sim de aprendizado individual. Há que se ressaltar tais diferenças.

Foi observado que existem locais físicos que favorecem às pessoas trocarem e compartilharem informações na empresa, embora alguns dos entrevistados considerem que os mesmos são pouco utilizados. Também foi possível observar que a empresa dedica atenção especial ao local de trabalho, preocupando-se com o layout e padronização de postos de trabalho. Não obstante, foi ressaltado por um entrevistado que o crescimento da empresa acabou por dificultar um pouco os encontros, pois segundo ele, apesar de existirem mais locais de encontro, os postos de trabalho ficaram distantes.

\footnotetext{
“O layout da empresa é totalmente preparado. Na antiga sede não havia nada disso. [...] Mas havia mais locais de encontro, inclusive porque todos trabalhavam num ambiente menor, por isso se viam mais, tomavam café todos ao mesmo tempo, pediam uma pizza, porque estavam todos perto. Hoje é raro isso acontecer. Agora, até mesmo pelo tamanho da empresa, criaram-se horários de lanches separados para se organizar a empresa." (Operacional 3)
}

Quanto à investigação de existência de processos estruturados ou formalizados que objetivem à $\mathrm{AO}$, as respostas foram negativas. Entretanto, foram observadas iniciativas informais, como subsídios para estudos em nível de graduação e pós-graduação, e, mais recentemente, incentivos para participação em seminários, palestras e workshops voltados ao core-business da organização.

Em relação à promoção de atividades internas como feiras, workshops, simpósios e seminários com o objetivo de promover a GC, foi identificado que aconteceu um workshop, uma única vez. Porém, foi identificada também a intenção da diretoria em realizar outros, e com maior freqüência, devido aos resultados positivos apurados nesta experiência.

$\mathrm{Na}$ empresa não foi identificado nenhum grupo de estudo, nem biblioteca. Entretanto, através da pesquisa documental, foi identificado um repositório de informações relevantes, através do "Manual do Produto", que permite aos funcionários se aprofundarem em seus conhecimentos relacionados ao produto da empresa.

Assim, as práticas de AO identificadas nesta pesquisa foram as seguintes: (1) Apoio à formação continuada: Graduação, Especialização; - com liberação de tempo e subsídio e (2) Programas internos de treinamento e desenvolvimento.

Ressalva-se novamente que a maioria das atividades direcionadas à $\mathrm{AO}$ identificadas foram práticas de aprendizagem individual, que podem ou não produzir efeitos na AO. 
Constata-se, pois, a existência de práticas de AO na empresa estudada, mesmo que de maneira informal. Entretanto, nenhuma COP foi identificada.

\section{Conclusões}

A presente pesquisa procurou investigar e analisar os processos e práticas de GC no contexto de uma média empresa do setor de seguros estabelecida no Brasil, que fossem compatíveis com as práticas e processos de GC relatados na literatura. Mais especificamente, investigou as práticas relativas a Monitoração Ambiental, Inteligência Competitiva, Gestão Estratégica da Informação, Gestão do Capital Intelectual, Aprendizagem Organizacional e Comunidades de Prática.

O pressuposto do trabalho baseava-se na percepção de que empresas de pequeno e médio porte poderiam não possuir um processo estruturado e formalizado de GC, embora fosse possível que tivessem, dentre suas atividades, processos, práticas e ferramentas de gestão que fossem compatíveis com os processos, práticas e ferramentas de GC relatadas na literatura.

Dessa forma, este trabalho investigou as práticas da GC no contexto de uma média empresa do setor de seguros, objetivando identificar a existência de práticas informais, e confrontando-as às práticas registradas na literatura. Para isso, utilizou-se como modelo direcionador o mapeamento conceitual integrativo de Alvarenga Neto (2005, 2008), que afirma que a promoção do conhecimento nas organizações deve considerar os três níveis hierárquicos que a compõem: estratégico, tático e operacional.

Em busca da resposta à pergunta de pesquisa balizadora do trabalho - Quais os processos e práticas de gestão existentes em uma média empresa brasileira do setor de seguros que são compatíveis com os processos e práticas de Gestão do Conhecimento relatadas na literatura? optou-se por uma abordagem qualitativa de pesquisa. Esta abordagem qualitativa foi orientada por um objetivo geral - Investigar e analisar as práticas de GC no contexto de uma média empresa do setor de seguros estabelecida no Brasil - que foi desdobrado em quatro objetivos específicos, sendo que cada objetivo específico originou uma categoria de análise.

Durante o trabalho, buscou-se em cada categoria de análise: identificar, descrever e analisar a existência ou não de cada prática relativa aos temas propostos neste estudo. Para isso foram levantados desdobramentos de cada um desses temas através do "Protocolo de Estudo de Caso". As evidências identificadas (ou mesmo a falta de evidências) foram tratadas com rigor através da triangulação de dados, até que se pudesse extrair resultados fidedignos e confirmados pela validade do construto, validade externa e confiabilidade.

A primeira constatação é da confirmação do pressuposto e também da pergunta de pesquisa a que se propôs a pesquisa aqui relatada, já que foram identificadas práticas gerenciais na empresa 
estudada que são compatíveis com as práticas de GC: Inteligência Competitiva, Monitoração Ambiental, Gestão Estratégica da Informação, Gestão do Capital Intelectual e Aprendizagem Organizacional. Como todos esses temas são frequentemente associados à literatura GC, conclui-se que a empresa possui processos e práticas de GC compatíveis com as relatadas na literatura, apesar desses não integrarem um processo formal e/ou estruturado de GC dentro da empresa.

Sendo assim, a partir de todas as análises realizadas, pode-se concluir que, embora não formalmente, a empresa XYZ valoriza, incentiva e, inclusive, pratica as atividades citadas, todas elas relacionadas às práticas de GC relatadas na literatura, porém desenvolvidas na empresa de maneira informal. Infere-se ainda que a empresa esteja apta a evoluir no desenvolvimento de práticas de GC por ter sido identificado na pesquisa, o interesse e a intenção do staff do seu nível estratégico em avançar por este caminho.

Essas constatações reafirmam o pressuposto inicial do trabalho, confirmando que empresas de pequeno e médio porte podem não ter um processo estruturado e formal de GC, embora possam ter, dentre suas atividades, práticas e ferramentas de gestão que são, sim, compatíveis com as práticas e ferramentas de GC relatadas na literatura. Tal assertiva implica na existência de um processo informal e desestruturado de GC.

Por fim, cumpre ressaltar que esta pesquisa não tem a pretensão de estabelecer verdades absolutas ou resultados que possam ser generalizados para outras empresas. A expectativa maior é que este trabalho incentive novos estudos e investigações similares em outras organizações, para que seja instigada a comparação de resultados.

\begin{abstract}
Investigates and analyses the existing processes and managerial/business practices in a medium brazilian firm from the insurance sector which are compatible with the existing ones in the Knowledge Management (KM) literature, assuming that $\mathrm{KM}$ can also be brought into existence as an informal and unstructured process. The qualitative research strategy is based on a single case study and three criteria were observed regarding the quality of the research project: construct validity, external validity and reliability. Multiple sources of evidence were used - semi-structured interviews, documental research and direct observation - and data analysis consisted of three flows of activities: data reduction, data display and conclusion drawing/verification based on evidences or premisses. The results confirmed de presumption and the conclusions suggest that - though not formally - the firm in this study encompasses sets of processes and managerial/business practices that are indeed compatilble wiht the existing ones in the KM literature. Henceforth, the firm in this single case study has reached a maturity stage that enables it to implement a formal KM process.
\end{abstract}

Key-words: knowledge management; managerial/business practices; small and medium firms; insurance sector.

\title{
Referências
}

ALVARENGA NETO, R. C. D. Gestão do conhecimento em organizações: proposta de mapeamento conceitual integrativo. 2005. 400 f. Tese (Doutorado em Ciência da Informação) - PPGCI, Escola de Ciência da Informação da UFMG, Belo Horizonte.

ALVARENGA NETO, R. C. D. Gestão do conhecimento em organizações: proposta de mapeamento conceitual integrativo. São Paulo: Saraiva, 2008. 
ALVARENGA NETO, R. C. D.; BARBOSA, R. R; CENDÓN, B. V. A construção de metodologia de pesquisa qualitativa com vistas à apreensão da realidade organizacional brasileira: estudos de casos múltiplos para proposição de modelagem conceitual integrativa. João Pessoa: Inf. \& Soc.: Est., João Pessoa, v.16, n. 2, jul./dez. 2006, p. 69-86. Disponível em: <http://www.ies.ufpb.br>. Acesso em 28 Mar. 2009.

BARBOSA, R. R. Inteligência empresarial: uma avaliação das fontes de informação sobre o ambiente organizacional externo. Data Grama Zero, v.3, n.6, dez. 2002. Disponível em <http:/www.dgz.org.Br/dez02/F_I_art.htm>. Acesso em 28 Mar. 2009.

BARBOSA, R. R. Monitoração ambiental: uma visão interdisciplinar. Revista de Administração, v.32, n.4, p. 42-53, out./dez., 1997.

CHOO, C. W. A organização do conhecimento: como as organizações usam a informação para criar significado, construir conhecimento e tomar decisões. 2. ed. São Paulo: SENAC, 2006.

DAVENPORT, E.; CRONIN, B. Knowledge management: semantic drift or conceptual shift? Journal of Education for Library and Information Science, 41(4): 294-306, 2000.

DAVENPORT, T. H. Ecologia da informação: por que só a tecnologia não basta para o sucesso na era da informação. São Paulo: Futura, 1998.

DAVENPORT, T. H., PRUSAK, L. Conhecimento Empresarial: como as organizações gerenciam o seu capital intelectual. Rio de Janeiro : Campus, 1998.

DILL, W. R. The impact of environment on organizational development. In: Concept and Issues in Administrative Behavior, eds. S. Mailick and E. H. Van Ness, 94-109. Englewood Cliffs, NJ: Prentice Hall, 1962.

MARCH, J. G.; SIMON, H. A. Limites cognitivos da racionalidade. In: Teoria das organizações. Rio de Janeiro: Editora Fundação Getúlio Vargas, 1975.

EDVINSSON, L.; MALONE, M. S. Capital Intelectual: descobrindo o valor real de sua empresa pela identificação de seus valores internos. São Paulo: Makron Books, 1998.

GARVIN, D. A. Building a learning organization. Harvard Business Review. Vol. 71 Issue 4, p. 78-91. Jul/Aug 1993.

MARCH, J. G.; SIMON, H. A. Limites cognitivos da racionalidade. In: Teoria das organizações. Rio de Janeiro: Editora Fundação Getúlio Vargas, 1975.

McGEE, J.; PRUSAK, L. Gerenciamento estratégico da informação: aumente a competitividade e a eficiência de sua empresa utilizando a informação como uma ferramenta estratégica. Rio de Janeiro: Campus, 1995.

MILES, M. B.; HUBERMAN, A. M. Qualitative data analysis: a sourcebook of new methods. Sage Publications, 1984.

SENGE, P. M.. A quinta disciplina: arte, teoria e prática da organização de aprendizagem. 6. ed. São Paulo: Best Seller, 2000.

SEBRAE - Serviço Brasileiro de Apoio às Micro e Pequenas Empresas. Boletim estatístico de micro e pequenas empresas: Observatório SEBRAE $\quad-\quad 1^{\circ}$ Semestre $2005 . \quad$ Disponível em: $<$ http://www.sebrae.com.br/customizado/estudos-e-pesquisas/estudos-e-pesquisas/boletim-estatistico-das-mpe >. Acesso em 28 Mar. 2009.

STEWART, T. A. Capital intelectual: a nova vantagem competitiva das empresas. 6. ed. Rio de Janeiro: Campus, 1998.

TRIVIÑOS, A. N. S. Introdução à pesquisa em ciências sociais: a pesquisa qualitativa em educação. São Paulo: Atlas, 1987.

VON KROGH, G.; ICHIJO, K.; NONAKA, I. Facilitando a criação de conhecimento: reinventando a empresa com o poder da inovação contínua. Rio de Janeiro: Campus, 2001. 
WENGER, E. C.; SNYDER, W. M. Comunidades de prática: a fronteira organizacional. Rio de Janeiro: Campus, 2001 .

WILSON, T.D. The nonsense of 'knowledge management'. Information Research, v.8, n.1, October, 2002.

YIN, R. K. Estudo de caso: planejamento e métodos. 2. ed. Porto Alegre: Bookman, 2001.

\section{Dados dos autores:}

Nome completo: André Augusto Barbosa Araújo

Filiação institucional: Centro Universitário UNA

Função ou cargo ocupado: Professor Assistente

Endereço completo para correspondência (bairro, cidade, estado, país e CEP): Rua Caraça, 684/601

- Bairro: Serra - Belo Horizonte-MG - Brasil - 30220-260

Telefones para contato: (31) 3036-3329 / (31) 3223-9516 / (31) 8833-6020

e-mail: andrearaujo.bh@gmail.com

Nome completo: Rivadávia Correa Drummond de Alvarenga Neto

Filiação institucional: Fundação Dom Cabral

Função ou cargo ocupado: Pesquisador e Professor

Endereço completo para correspondência (bairro, cidade, estado, país e CEP): Avenida Princesa

Diana, 760 - Alphaville Lagoa dos Ingleses - Nova Lima-MG - 34000-000

Telefones para contato: (31) 9127-4578

e-mail: rivadavia@fdc.org.br

Recebido para publicação em: 12/09/2009

Aceito para publicação em: 05/11/2009 